\title{
Ajuste Plurianual de Salarios
}

¿BENEFICIOS 0 RIESGOS?

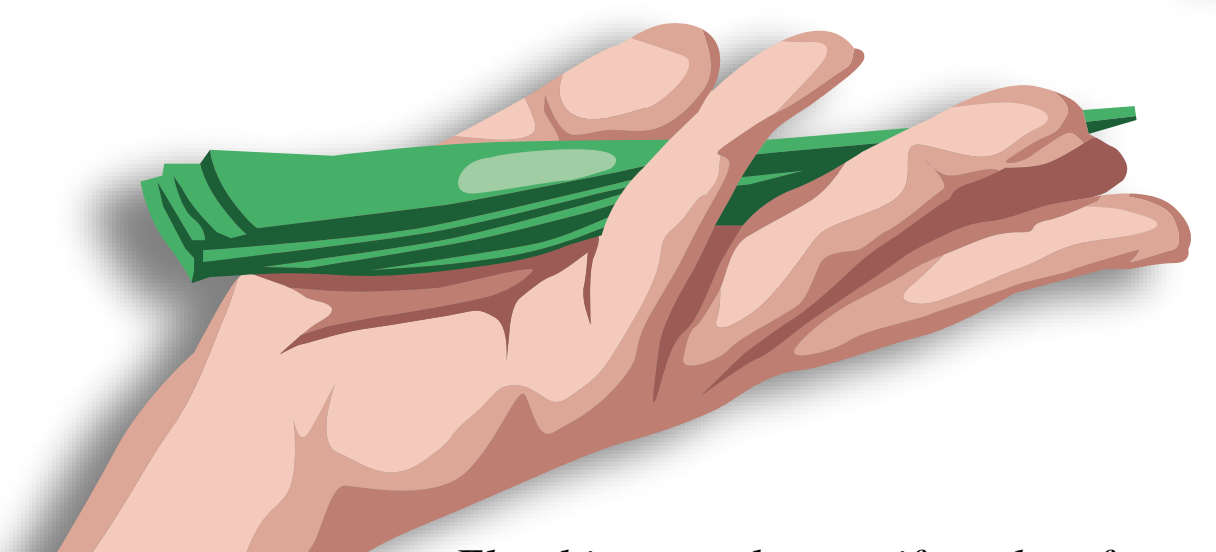

El gobierno se ha manifestado a favor del modelo plurianual, con la intención de dejar determinado los ajustes del salario mínimo para los próximos 3 o 4 años. La naturaleza de esta clase de acuerdos nos lleva a discutir dos asuntos económicos cruciales para el éxito o el fracaso de este tipo de propuestas.

Por Lucas Navarro, PhD en Economía, Georgetown University, EE.UU., académico FEN UAH Carlos J. Ponce, Ph.D. en Economía, University of California at Los Angeles, EE.UU., académico 
rio mínimo a lo largo del tiempo. En un contexto de mediano plazo, la CUT planteó que el salario mínimo debiera alcanzar los 420 mil pesos mensuales. Considerando la información presentada en el cuadro 1, ese nivel del salario mínimo sería 1.63 veces superior al de 2016. Dada la magnitud de estas cifras conviene examinar si (a) el salario mínimo ha evolucionado de acuerdo a la productividad laboral y si (b) el tipo de negociación -anual versus plurianual- tiene algún efecto sobre esta materia.

El gráfico 1 muestra el crecimiento del PIB y del salario mínimo en términos reales entre 1990 y 2017. Los datos comprueban que en los años en los que el ajuste del salario mínimo fue anual, el mismo creció, en promedio, por debajo del PIB, mientras que en los años en donde el ajuste fue plurianual, el salario mínimo nunca creció por debajo del PIB. Más aún, las últimas dos experiencias de ajustes plurianuales fueron 'buenas' en el sentido de que la evolución del salario mínimo fue similar a la de la actividad económica. Estas primeras observaciones sugieren que las negociaciones plurianuales no tienen por qué distorsionar la relación a largo plazo entre salario y productividad y poner en riesgo el empleo de los trabajadores de menores recursos.

No obstante, la primera experiencia de ajustes plurianuales fue negativa. En junio de 1997, en el marco del buen contexto macroeconómico, se estableció un incremento nominal de $30 \%$ del salario mínimo para tres años que ante la posterior recesión durante la crisis asiática terminó siendo excesivo y habría contribuido a potenciar la destrucción de empleos de baja calificación. En efecto, entre 1998 y 2000 el salario mínimo aumentó $24 \%$ en términos reales y la actividad económica creció un $9 \%$. La tasa de desempleo pasó de un promedio de $6.1 \%$ en 1997 a $9.8 \%$ en 1999, y luego tardó muchos años en reducirse, aun luego de la recuperación de la actividad económica. Esta experiencia nos deja al menos dos enseñanzas respecto al modelo plurianual de negociación.

En primer lugar, que contingencias económicas negativas y exógenas son, muchas veces, difícil de anticipar y que como consecuencia se puede generar un desacople en el mediano plazo entre productividad y salario mínimo. No hace falta remarcar los consiguientes efectos negativos que este tipo de distorsiones generan sobre el empleo.

Segundo, que un shock negativo de corto plazo puede generar un aumento en el desempleo que se perpetúe a mediano y largo plazo. En nuestra opinión, este problema está íntimamente vinculado al reparto de riesgo entre empresas y trabajadores a lo largo del ciclo económico.

Un salario fijo plurianual funciona como un seguro total provisto por las empresas para

\section{"Un ajuste responsable del salario mínimo debe velar por el bienestar de los trabajadores teniendo en cuenta no solamente que el ingreso alcance para brindar un mínimo de bienestar, sino que también sea viable"}

los trabajadores. ¿Es este reparto de riesgo eficiente? La teoría económica muestra que un reparto óptimo del riesgo depende de las actitudes de los individuos frente al mismo. Parece natural asumir que trabajadores poco calificados y con escaso acceso a mercados financieros 'sufren' aversión al riesgo. Entonces, si la empresas fueran neutrales al riesgo (como lo son las grandes firmas que disponen de activos líquidos y acceso en condiciones favorables a mercados financieros internacionales), los salarios fijos plurianuales repartirían óptimamente el riesgo entre empleados y empleadores.

¿Pero son las empresas (en la que se desempeñan los trabajadores que perciben el salario) neutrales al riesgo? En otras pala- bras: ¿Es eficiente que estas empresas se encarguen de absorber completamente los shocks económicos negativos? Como se dijo antes, jel 75\% de los trabajadores que percibe el salario mínimo trabaja en empresas con menos de 10 empleados! Es claramente una fantasía suponer que este modelo de empresas cuasi-familiares y con limitado acceso a los mercados crediticios esté en condiciones de asegurar completamente a sus trabajadores. Ante shocks negativos, acuerdos salariales como estos pueden terminar en el cierre de este tipo de establecimientos y la consecuente pérdida de empleos. Aún más, la posterior reapertura de esta clase de empresas puede ser lenta y generar una persistencia en el desempleo de los trabajadores más necesitados.

En definitiva, un ajuste responsable del salario mínimo debe velar por el bienestar de los trabajadores teniendo en cuenta no solamente que el ingreso alcance para brindar un mínimo de bienestar, sino que también sea viable. Un salario demasiado alto y por encima de la productividad de los trabajadores puede derivar en la destrucción de empleo y pérdida total del ingreso, lo que termina perjudicando, más que ayudando, a los trabajadores. De igual manera, el reparto del riesgo promovido por el modelo plurianual puede terminar perjudicando a los trabajadores ya que las empresas que los emplean no están preparadas para absorber completamente shocks económicos negativos.

La propuesta de la CUT de alcanzar un salario mínimo de 420 mil pesos requiere ser analizada con sumo cuidado. De ninguna manera, deben dejarse de lado los potenciales riesgos que acarrea cuando los supuestos sobre los que se determinan los ajustes no se cumplen, tal como ocurrió a fines de los noventa en Chile. Para evitar estos efectos indeseados, la formula debiera contar con cierta flexibilidad que permitiera adaptar la regla en caso de que sea necesario enfrentar shocks económicos adversos. $\mathbf{E}$ 